\title{
A hemocyte gene expression signature correlated with predictive capacity of oysters to survive Vibrio infections
}

\author{
Rafael Diego Rosa ${ }^{1,2}$, Julien de Lorgeril ${ }^{1}$, Patrick Tailliez ${ }^{3}$, Roman Bruno ${ }^{4}$, David Piquemal ${ }^{4}$ and Evelyne Bachère ${ }^{1 *}$
}

\begin{abstract}
Background: The complex balance between environmental and host factors is an important determinant of susceptibility to infection. Disturbances of this equilibrium may result in multifactorial diseases as illustrated by the summer mortality syndrome, a worldwide and complex phenomenon that affects the oysters, Crassostrea gigas. The summer mortality syndrome reveals a physiological intolerance making this oyster species susceptible to diseases. Exploration of genetic basis governing the oyster resistance or susceptibility to infections is thus a major goal for understanding field mortality events. In this context, we used high-throughput genomic approaches to identify genetic traits that may characterize inherent survival capacities in C. gigas.
\end{abstract}

Results: Using digital gene expression (DGE), we analyzed the transcriptomes of hemocytes (immunocompetent cells) of oysters able or not able to survive infections by Vibrio species shown to be involved in summer mortalities. Hemocytes were nonlethally collected from oysters before Vibrio experimental infection, and two DGE libraries were generated from individuals that survived or did not survive. Exploration of DGE data and microfluidic qPCR analyses at individual level showed an extraordinary polymorphism in gene expressions, but also a set of hemocyte-expressed genes whose basal mRNA levels discriminate oyster capacity to survive infections by the pathogenic V. splendidus LGP32. Finally, we identified a signature of 14 genes that predicted oyster survival capacity. Their expressions are likely driven by distinct transcriptional regulation processes associated or not associated to gene copy number variation (CNV).

Conclusions: We provide here for the first time in oyster a gene expression survival signature that represents a useful tool for understanding mortality events and for assessing genetic traits of interest for disease resistance selection programs.

Keywords: Marine invertebrate, Mollusk bivalve, Mass mortality, Transcriptome-wide analysis, Digital gene expression, Microfluidic qPCR, Survival signature, Polymorphism, Gene copy number, Survival predictive biomarkers

\section{Background}

Since the mid-1970s, large-scale episodic events such as harmful algal blooms and other microbial outbreaks, disease epidemics and mass mortalities have occurred in marine environments at a historically unprecedented rate, and may reflect environmental changes and an unfavorable energetic balance in animals [1]. Anthropogenic global changes (climate warming, pollution, introduced

\footnotetext{
* Correspondence: ebachere@ifremer.fr

${ }^{1} 1$ llfremer, CNRS, Université Montpellier 2, IRD and Université Montpellier 1, UMR 5119 "Laboratoire Écologie des Systèmes Marins Côtiers, Place Eugène Bataillon, PO Box 34095, Montpellier, France

Full list of author information is available at the end of the article
}

species) have been implicated as contributors to disease outbreaks in marine ecosystems worldwide. One aspect of these changes is shifts in natural systems, altering inter-organism dynamics including many host-pathogen interactions and leading to the establishment of new diseases or increased pathogenicity and virulence of established diseases [2]. These emerging infectious diseases have been recently recognized as a threat, not only to humans, but also to global biodiversity [3].

It is widely established that the susceptibility of organisms to infection is determined by a complex balance of environmental and host factors. Disturbances of this equilibrium may result in multifactorial diseases as

\section{Biomed Central}


currently shown in marine invertebrates [4]. Pacific oysters Crassostrea gigas have repeatedly suffered abnormal mortalities during the summer months around the world. Collectively, these mortality events are called summer mortality syndrome, a phenomenon that has been suggested to have a multifactorial etiology, resulting from the combination of multiple biotic and abiotic factors. Those factors include the environment (trophic conditions, elevated water temperature), aquaculture practices, oyster genetics and physiology, reproductive effort followed by spawning and the presence of opportunistic microorganisms [5]. Since 2008, an herpesvirus, OsHV-1 (for Ostreid herpesvirus type 1) [6,7], and various Vibrio species [8] have been systematically associated with these abnormal mortalities.

Understanding the role of genetic basis in oyster resistance or susceptibility to infection should deeply contribute to identify the causes of mortalities and the traits that characterize enhanced survival capacities in oyster populations. In recent years, high-throughput genomic approaches have greatly improved knowledge on the genetic basis governing the mechanisms of resistance to infectious diseases, a major challenge for the modern human and veterinary medicine. Several studies have supported a significant role for host genetics in differential susceptibility to many human infectious diseases such as tuberculosis, leprosy, hepatitis, malaria and also AIDS $[9,10]$. Genome-wide studies have evidenced genomic polymorphic regions (Single Nucleotide Polymorphism or SNP) correlated to changes in the susceptibility to some infectious agents [11]. In the recent years, genomic features such as gene copy number variations (CNV) and transcriptional signatures [12,13] have been extensively investigated as contributing to disease susceptibility or resistance phenotypes. Transcriptional (or gene expression) signatures comprise a combination of genes whose expression patterns are markers of a physiological status $[12,14]$. In human medicine, gene expression signatures have substantially aided in the diagnosis of cancer and the risk of developing active tuberculosis [12,14-16].

Here, we have investigated potential genetic basis for $C$. gigas resistance to Vibrio infections by high-throughput transcriptomic and genomic approaches. For this non model species, the whole genome sequence is still not published [17] but 29,745 unique EST sequences are publicly available (http://public-contigbrowser.sigenae.org:9090/ Crassostrea_gigas/index.html) [18]. Thus, we applied the DGE (Digital Gene Expression) deep-sequencing technology. Similar to the massively parallel signature sequencing (MPSS) approach [19], the DGE tag-based approach provides large-scale data sets to establish a complete quantitative and qualitative analysis of cell transcriptome without prior knowledge of genome annotation [20]. In a previous study, the DGE technology was successfully applied for the characterization of defense mechanisms related to the oyster successful response and survival to virulent Vibrio infections [21]. Here, the aim was to identify a combination of genes whose inherent basal expression can predict the oyster capacity to survive infections. For that, the hemocytes (immunocompetent cells) have been collected from oysters before an infection by virulent Vibrio strains isolated during summer mortality episodes [8]. Further monitoring of mortalities allowed classifying samples with contrasted phenotypes of survival or non survival capacity that have been used for the construction of DGE libraries devoted to a predictive character of oysters to circumvent Vibrio infection. Through the exploration of DGE data and individual gene expression study by microfluidic qPCR devices [22], we have evidenced a 14-gene survival signature. Besides, we show here for the first time an extraordinary individual polymorphism of hemocyte basal gene expression in oysters.

\section{Results}

\section{Hemocyte transcriptome of oysters with an inherent capacity to survive Vibrio infections}

A nonlethal sampling method for hemolymph collection [23] was applied to obtain the hemocyte basal gene expression profile before a challenge by pathogenic bacteria. Hemocyte samples were collected from 180 tagged oysters that were further experimentally infected after an 8-day recovery. Vibrio strains, V. splendidus LGP32 (8 x 10 7 CFU/ oyster) or $V$. aestuarianus LPi 02/41 ( $2 \times 10^{7}$ CFU/oyster), which were isolated during 2006 summer mortality episodes in France, were used for experimental infections. Survival rates were $59 \%$ and $33 \%$ (at day 4) for animals infected by $V$. splendidus LGP32 and $V$. aestuarianus LPi 02/41, respectively. Hemocyte mRNA samples collected prior to Vibrio infection were then categorized according to oyster survival. Thus, two DGE libraries were constructed from hemocytes of oysters able or not able to survive Vibrio infections. They were named SVir-8d [GEO: GSM667902] and NSVir-8d [GEO: GSM667901], respectively.

A total of 3,605,503 and 3,850,124 tag sequences (17-bp) were obtained from the whole sequencing of SVir-8d and NSVir-8d libraries, respectively, corresponding to 56,879 unique tags. A comparison of tag occurrences (incidence of each tag in libraries) revealed that 5,212 unique tags were differentially represented between libraries ( $>5$-fold change) (Figure 1A). Tag-mapping was performed against the $C$. gigas EST database $(29,745$ unique sequences: 7,940 contigs and 21,805 singletons) containing 13,898 ESTs from hemocytes [18]. From the 1,049 EST-matched sequences, only 385 sequences showed homologies to known proteins. Thus, no striking relationship between biological functions and oyster 


\begin{tabular}{|c|c|c|}
\hline A & SVir-8d & NSVir-8d \\
\hline Total of sequenced tags & $3,605,503$ & $3,850,124$ \\
\hline Unique tags & \multicolumn{2}{|c|}{56,879} \\
\hline Tags differentially represented (>5-fold change) & \multicolumn{2}{|c|}{5,212} \\
\hline Specific tags (>5-fold change) & 1,624 & 1,304 \\
\hline Crassostrea gigas EST database (GigasDataBase) matches & \multicolumn{2}{|c|}{1,049} \\
\hline Sequences with predicted functions & \multicolumn{2}{|c|}{385} \\
\hline Sequences with unknown functions & \multicolumn{2}{|c|}{664} \\
\hline
\end{tabular}

B

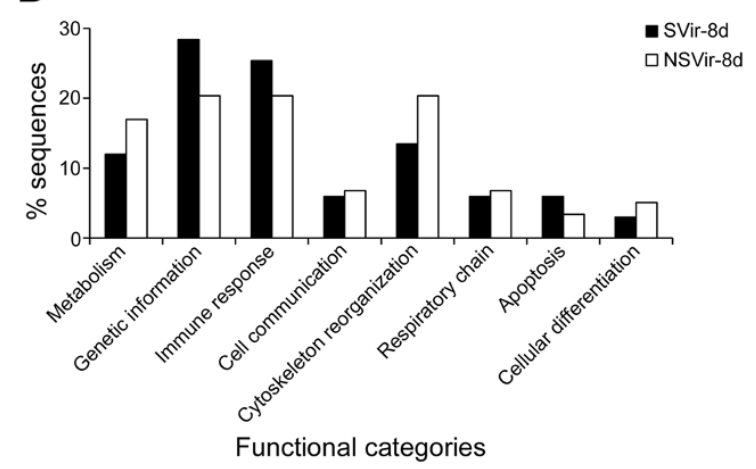

Figure 1 Hemocyte transcriptome of oysters with distinct capacities to survive Vibrio infections. (A) General characteristics of DGE libraries generated from oysters able (SVir-8d) and not able (NSVir-8d) to survive infections by the pathogens Vibrio splendidus LGP32 and $V$. aestuarianus LPi 02/41. (B) Functional annotation of EST-matched sequences differentially represented between DGE libraries ( $>5$-fold change).

capacity to survive infections was clearly evidenced. However, the SVir-8d library appears to be more enriched in genes related to genetic information processing and immune response compared to NSVir-8d, which was enriched in metabolism and cytoskeleton reorganization (Figure 1B).

\section{Oyster hemocyte transcriptome-wide analysis reveals a high polymorphism in basal gene expression at individual level}

To assess whether gene expression profiles were related to survival capacity phenotypes, we have explored the DGE data on individual oysters by high-throughput microfluidic qPCR approach [22]. Three new independent experimental infections were conducted to obtain individual hemocyte samples from oysters able ( $\underline{S})$ and not able (NS) to survive infection, as previously done for DGE library construction. We focused on $V$. splendidus which has been shown dominant in field mortalities, since 2009, comparatively to $V$. aestuarianus. Final survival rates of $50 \%$ were obtained and, among the 180 hemolymph samples issued from the three independent infections, 90 samples, corresponding to 45 oysters for each phenotype, yielded high quality RNA suitable for further analyses.
A total of 280 hemocyte-expressed genes were chosen from the 1,049 sequences differentially expressed ( $>5$ fold change) between SVir-8d and NSVir-8d DGE libraries. Both GenBank annotated (62\%) and non-annotated (38 \%) sequences were considered. The technical efficiency of three independent 96.96 dynamic arrays was assessed by measuring the expression of the three reference genes in each qPCR chip (ANOVA test). Then, the expression profile of the selected genes was assessed to compare their mRNA abundance according to the oyster survival phenotypes (S versus NS) at the individual level. Surprisingly, the analysis of the large qPCR data set revealed an extraordinary interindividual variability in gene expressions for most of the transcripts measured. As illustrated in Figure 2A, striking inter-individual differences in basal gene expression were seen for some genes with up to 20-fold change, for example, for the follistatin. To our knowledge, such a high inter individual variability in basal gene expression has never been previously reported in oysters.

Additionally, the high-throughput qPCR analyses revealed numerous genes whose basal levels of expression could not be detected in some individuals (Figure 2B). Interestingly, those GenBank annotated sequences appeared to correspond to genes involved in immune responses, including an interferon-induced protein 44-like, a tumor necrosis factor ligand superfamily member 10 (TNFSF10), a member of oyster lysozymes (Cg_lysoz2), a baculoviral inhibitor of apoptosis repeatcontaining protein 3 homologue (BIRC3) and members of the big defensin antimicrobial peptide family ( $\mathrm{Cg}$-BigDef) [24]. However, no significant relationships could be found between the expression detection of these genes and the $\mathrm{S}$ or NS phenotypes (ANOVA test).

\section{A hemocyte 14-gene expression signature as a predictor of oyster survival capacity}

We have investigated the correlation between the profiles of hemocyte basal gene expression and the oyster survival capacity by the analysis of the mRNA abundance of genes presenting exploitable quantitative values $(5 \leq \mathrm{Cq} \leq 25)$. Due to well known oyster DNA sequence polymorphism, rigorous melting curve analysis was required to ensure qPCR specificity and avoid misinterpretations of gene expression data [25]. Thus, we only considered the qPCR data of 233 genes, from the 280 initial ones, expressed in the $45 \mathrm{~S}$ and $45 \mathrm{NS}$ individual oysters. In spite of the high gene expression polymorphism, statistical partial least-squares (PLS) regression $[26,27]$ analysis revealed that the basal expression levels of a core set of genes were associated to S or NS phenotypes (Figure 3A). To refine our analysis, we further considered only those genes that did not display high individual variability of basal expression among the 


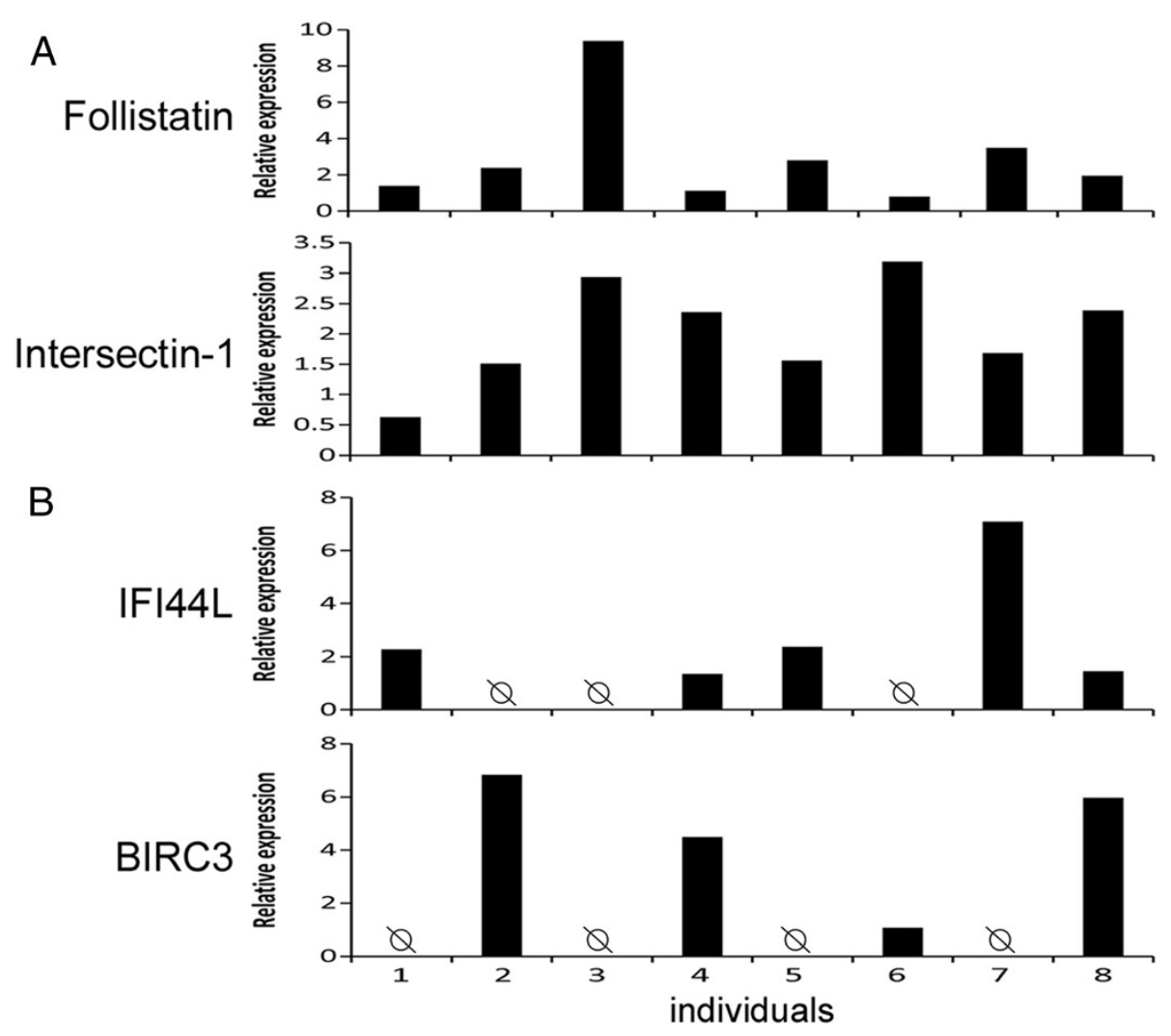

Figure 2 Basal gene expression polymorphism. Relative mRNA abundances of four hemocyte genes in eight individual oysters are shown as examples of (A) individual differences in basal gene expressions (follistatin and intersectin-1); (B) presence or absence (Ø) of basal expression for an interferon-induced 44-like protein (IFI44L) and a baculoviral inhibitor of apoptosis repeat-containing protein 3 homologue (BIRC3). Note that each individual displays a unique profile of gene expression for these four transcripts. Relative expression levels were calculated according to the $2^{-\Delta \Delta C a}$ method normalized with the ribosomal L40 protein ( $\mathrm{g}$-rp/40).

oysters from a same phenotype. Thus, the combination of the mRNA abundance of 50 genes was identified that comprises a set of 19 genes highly transcribed in the $\mathrm{S}$ phenotype and a set of 31 genes highly transcribed in the NS phenotype (Additional File 1).

The expression profile of these 50 hemocyte-expressed genes (from two technical replicates) was further used to foresee oyster survival using the expression data from oysters from both survival phenotypes. The X-loadings $\left(\mathrm{w}^{*}\right)$ corresponding to the data generated by $\mathrm{qPCR}$ and the Y-loadings (c) corresponding to the oyster S and NS phenotypes are presented in Figure 3B. The applied PLS model segregated most of the 90 individuals according to their survival capacity $\left(R^{2} Y=0.831\right)$ (Figure $3 B$ ). To identify the hemocyte transcripts statistically related to each phenotype, we additionally applied appropriated fold change cut-offs ( $x>1$.7-fold change for overexpression and $\mathrm{x}<0.7$-fold change for underexpression). Mann-Whitney test $(\alpha=0.09)$ was performed individually on the 50 genes associated to the survival phenotypes. Thus, $\Delta \mathrm{Cq}$ which are the most reproducible values were processed to assess a significant difference between $\mathrm{S}$ and NS survival phenotypes. Among the selected candidates, the expression profiles of 14 genes appeared to be significantly associated to an inherent capacity to survive infections (Table 1). Thus, we can presume that one individual with high probabilities to survive Vibrio infections transcribes at high levels the seven genes associated to the $S$ phenotype, and concurrently at low levels the seven genes associated to the NS phenotype. Oysters from the NS phenotype (not able to survive infections) displayed an inverse pattern in gene expression profile for the survival signature. In the view of our findings, this 14-gene survival signature is able to predict the oyster survival capacity to infections by the pathogenic $V$. splendidus LGP32.

mRNA abundance of the 14-gene markers is revealing an inherent genetic trait rather than a particular physiological status

We confirmed that the survival signature revealed an inherent genetic trait in oysters rather than a pre-stimulation or a physiological response. Indeed, high mRNA abundance of the genes of the signature could have resulted 

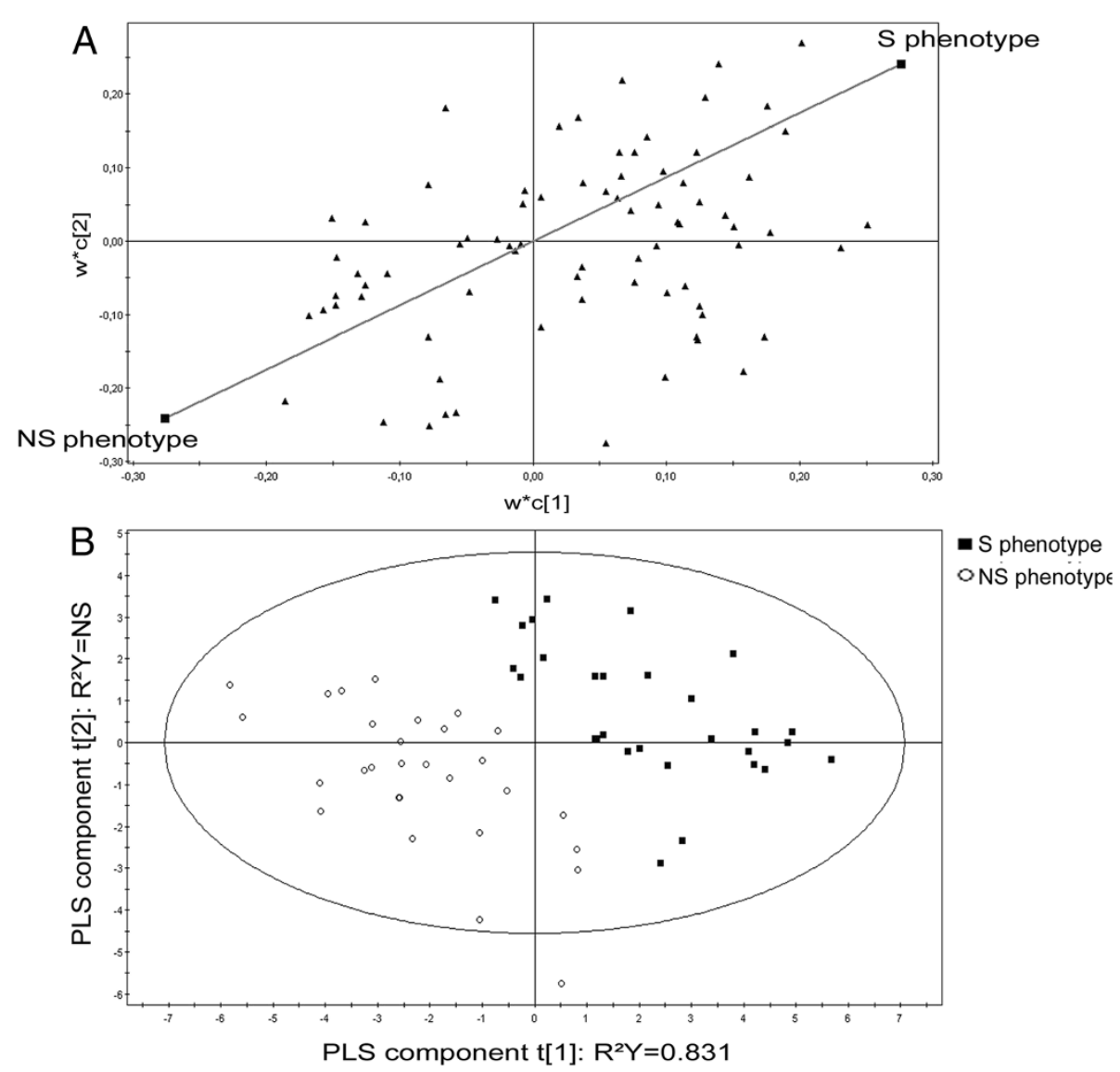

Figure 3 Partial least-squares (PLS) discrimination between hemocyte-expressed genes and oyster survival phenotypes (Survival and Non-Survival). (A) The graphic shows the $X$-loadings ( $W^{*}$ ) of the $X$ variables ( $q P C R$ data) and the $Y$-loadings (c) of the $Y$ variables ( $S$ and NS phenotypes), and thereby shows the relationship between $X$ and $Y$ variables. The variables $X$ (black triangles) and $Y$ (black squares) combine in the projections, and the variables $X$ relate to the variables $Y$. (B) Relationship between hemocyte-expressed genes and oysters from $S$ or NS phenotypes using PLS regression. The cross-validation led to two components represented as t[1] and t[2].

from an increase in gene transcription for some individuals before the experiment. For that, oysters (3 pools of 10 animals/conditions) were injected with a sublethal dose of $V$. splendidus LGP32 (5 $\times 10^{7} \mathrm{CFU} /$ animal) or sterile sea water (SSW). Non injected oysters were used as a control. As previously reported, a great variability in transcript rates was observed for both unchallenged and immune challenged (Vibrio or SSW) oysters. Two main types of expression profiles were obtained among the signature genes (Figure 4). Nine genes displayed no changes in transcript abundance at $24 \mathrm{~h}$ following either bacterial or SSW injection, compared to unchallenged animals as illustrated for multiple EGF-like domains 10 and cytochrome $c$ (Figure 4). Besides, five genes, including the unknown BQ427036.1.a.cg2 and zinc finger HIT domain-containing protein 3 shown in Figure 4 as examples, displayed a decrease of transcript abundance in circulating hemocytes following both the bacterial and SSW injection, thus independently of an acute response to the Vibrio. No up-regulation was seen for any of the
14 hemocyte-expressed genes following the bacterial challenge or SSW injection. Thus, mRNA abundance of the 14 genes of the survival signature reveals, in oysters, basal gene expression independent from their physiological response.

\section{Polymorphism in hemocyte basal gene expression can be associated to variations in gene copy numbers in oyster genome}

In an attempt to understand the genetic basis involved in the transcriptional regulation of the genes associated to oyster survival, we investigated whether variability in gene expression would reflect gene copy number variations $(\mathrm{CNV})$ in oyster genome. A relative quantification approach was developed to verify a potential correlation between gene copy abundance and mRNA expression of the oyster survival signature. For that, both genomic DNA and total RNA were extracted from ten oysters showing striking differences in gene expression of seven genes from the 14-gene survival signature for which 
Table 1 List of the hemocyte-expressed genes comprising the Crassostrea gigas 14-gene survival signature

\begin{tabular}{|c|c|c|c|c|}
\hline \multirow[t]{2}{*}{ C. gigas Sigenae contig } & \multicolumn{2}{|l|}{ BlastX best hit } & \multicolumn{2}{|c|}{ Expression statistics } \\
\hline & Name [species] & E-value (\% identity) & Level.err & $P$-value \\
\hline \multicolumn{5}{|l|}{ S phenotype } \\
\hline wy0aaa40yd07fm1.1.a.cg.2 & Phosphoserine aminotransferase 1 [Haliotis discus discus] & $2 e-78(66 \%)$ & 0.28622 & 0.03846 \\
\hline BQ427036.1.a.cg.2 & Unknown gene product & - & 0.38399 & 0.00302 \\
\hline wy0aba24ye12fm1.1.a.cg.2 & Unknown gene product & - & 0.55408 & 0.03746 \\
\hline wy0aba17yo09fm1.1.a.cg.2 & Cystatin A2 [Dictyostelium discoideum] & $4 \mathrm{e}-13(52 \%)$ & 0.35958 & 0.02324 \\
\hline wy0aba10yp04fm1.1.a.cg.2 & Multiple EGF-like domains 10 [Mus musculus] & 2e-07 (33 \%) & 0.39222 & 0.08030 \\
\hline wy0aba11yk24fm1.1.a.cg.2 & Unknown gene product & - & 0.44713 & 0.01984 \\
\hline wy0aba11yc21fm1.1.a.cg.2 & Unknown gene product & - & 1.87451 & 0.08814 \\
\hline \multicolumn{5}{|l|}{ NS phenotype } \\
\hline cdn37p0015o06_f.1.a.cg.2 & Zinc finger HIT domain-containing protein 3 [Danio rerio] & $2 \mathrm{e}-22(42 \%)$ & 0.05424 & 0.07887 \\
\hline wy0aba18yb03fm1.1.a.cg.2 & Unknown gene product & - & 0.07867 & 0.02879 \\
\hline wy0aba9yd1 1 fm1.1.a.cg.2 & Poly(U)-specific endoribonuclease-D [Xenopus laevis] & $9 e-12(47 \%)$ & 0.05678 & 0.00460 \\
\hline wy0aaa27yp20fm1.1.a.cg.2 & Unknown gene product & - & 0.05616 & 0.02180 \\
\hline cdn20p0004b10.f.1.a.cg.2 & Unknown gene product & - & 0.14109 & 0.06483 \\
\hline cdn20p0005d09.f.1.a.cg.2 & Unknown gene product & - & 0.06659 & 0.04859 \\
\hline oygd10b10d19r1_m13rev.1.a.cg.2 & Cytochrome c [Pectinaria gouldi] & $6 e-49(85 \%)$ & 0.08880 & 0.00854 \\
\hline
\end{tabular}

pairs of primers present same efficiency and specificity on gDNA and cDNA. Variations in gene copy number were shown for all analyzed genes. Higher variations in gene copies (from 4.5 to 120 -fold changes) than in expression levels (from 2.2 to 16 -fold changes) were seen for four genes (as example Figures 5A and 5D). Conversely, for the other three genes, the variations in expression were higher (from 4.5 to 250 -fold changes) than in gene copy number (from 2 to 6 -fold changes) (as example Figures 5B and $5 \mathrm{C}$ ). Finally, among those seven genes, only two presented positive correlation $(p<0.05)$ between the relative abundance of gene copy and relative gene expression (Figures 5A and 5B).

\section{Discussion}

Herein, we successfully identified a 14-gene survival signature, a cluster of hemocyte-expressed genes whose basal expression profile was predictive of the oyster capacity to survive Vibrio infections. This study provides the first evidence that oyster survival to infectious diseases can be driven by genetic determinants. We revealed an extraordinary interindividual polymorphism in basal gene expression that is associated to an inherent capacity of some oysters to survive Vibrio infections.

In previous work, we applied DGE to highlight immune functions involved in the successful response of C. gigas to circumvent virulent Vibrio strain infections compared to a non virulent one [21]. Here, the aim was to evidence gene markers of an inherent survival capacity rather than to characterize biological functions or molecular mechanisms implicated in that capacity. We just observed an enrichment of genes related to immune response and genetic information processing in the SVir-8d DGE library. The comparative analysis of the hemocyte transcriptomes of oysters able (SVir-8d) or not able (NSVir-8d) to survive did not highlight striking functional categories as potentially involved in oyster health promotion and conferring advantageous capacity to survive infections. This is not surprising considering the low number of sequences found with predicted functions (only 385 instead of 664 with unknown functions). With further progress in the genetic resources in C. gigas, one can return to exploit the DGE data and expect to characterize unambiguously biological functions associated with oyster fitness and optimal survival capacity.

The comprehensive and detailed quantitative analysis of the DGE data at the individual level has shown here for the first time in oysters the remarkable interindividual polymorphism in hemocyte gene expression. It is illustrated by great variations in basal mRNA levels up to 20-fold change between individuals. In human, variations in the basal mRNA abundance of some key genes represent an important genetic basis underlying several physiological traits that includes resistance (or susceptibility) to many known infectious diseases [14]. Moreover, in many oysters from both survival phenotypes, basal mRNA levels of some immune-related genes were not detected. It cannot be ruled out that due to a high level of DNA polymorphism, only transcripts encoded by particular alleles could have been amplified [25]. Indeed, it is widely recognized that oysters are one of the highest 


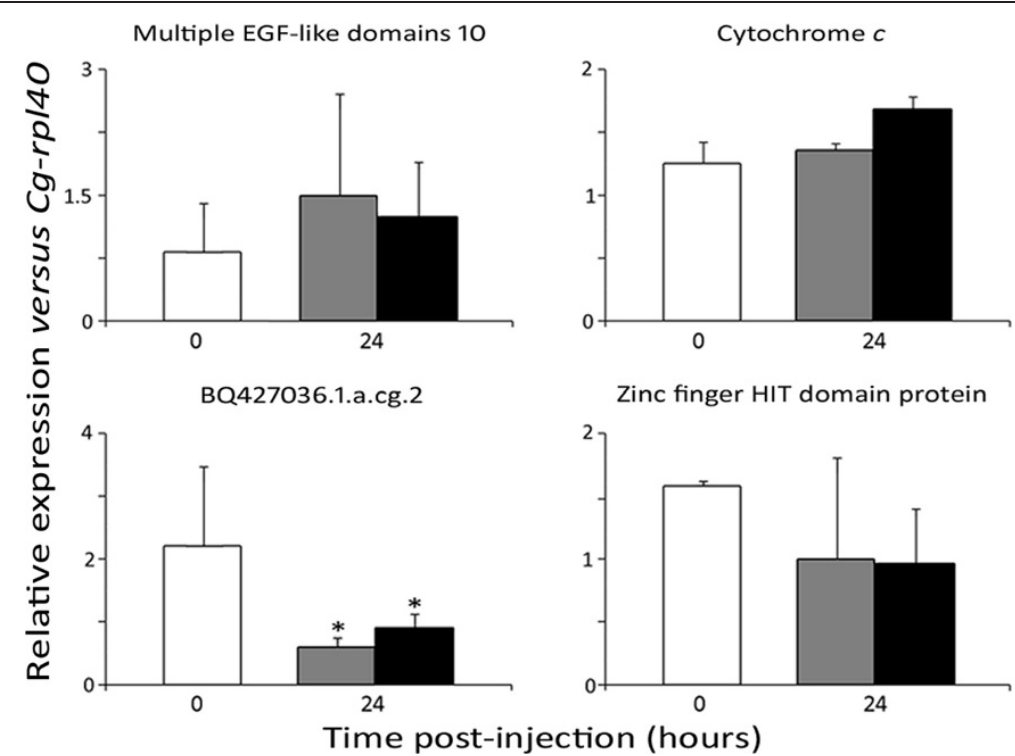

Figure 4 Relative expression profile of transcripts from the 14-gene survival signature following oyster challenge. The two types of expression profiles obtained are illustrated taking 4 genes among the signature, as examples. Hemocyte gene expression was analyzed by qPCR in unchallenged oysters (white bars) and in oysters $24 \mathrm{~h}$ after Vibrio splendidus LGP32 (black bars) or sterile sea water (grey bars) injection. Results are presented as mean values from 10 individuals per conditions. Relative expression levels were calculated according to the $2^{-\Delta \Delta c a}$ method normalized with the ribosomal $\mathrm{L} 40$ protein $\left(\mathrm{Cg}\right.$-rp/40). Asterisks $\left(^{*}\right)$ indicate significant differences of gene expression between conditions $(P<0.05)$.

polymorphic species in the animal kingdom (one SNP every $40 \mathrm{bp}$ in genomic non-coding regions) $[17,28]$. Moreover, most of transcripts whose expression was shown to be absent among individuals corresponded to immune-related proteins, which have been shown in $C$. gigas to display a high level of sequence diversity [29]. Another hypothesis is that some of these genes are not expressed in some individuals because of the absence of

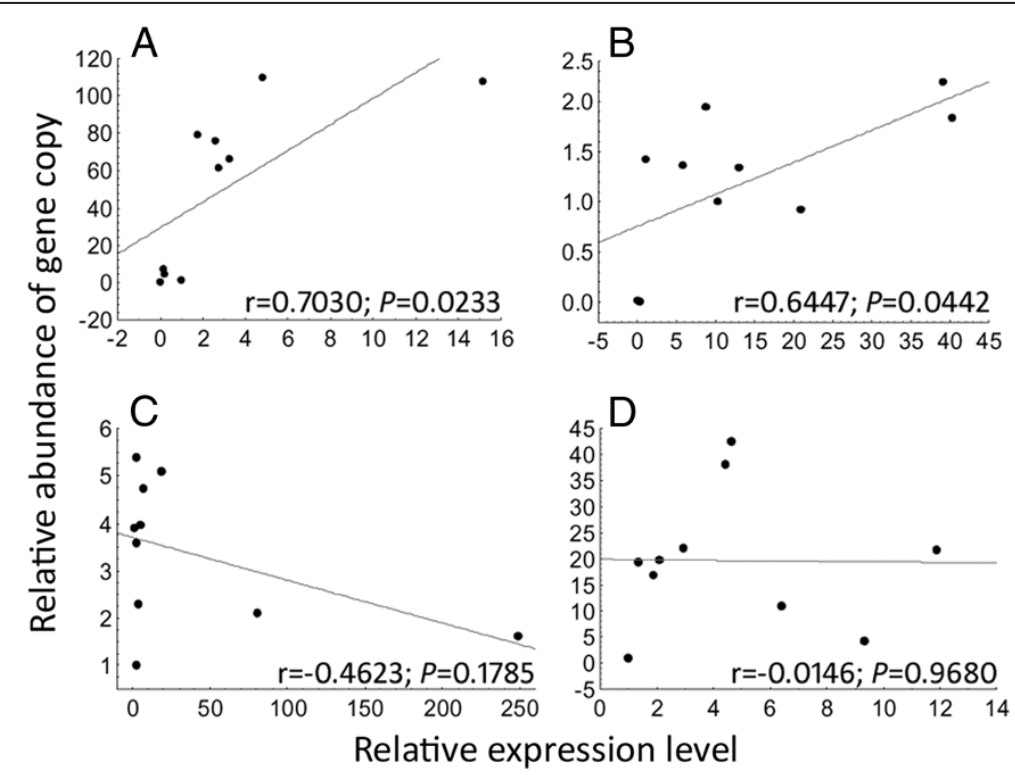

Figure 5 Examples of correlations between relative abundance of gene copy and basal gene expression levels for four gene markers. Relative expression and gene copy abundance were estimated by qPCR at individual level $(n=10)$ for $(\mathbf{A})$ wy0aba11yc21fm1.1.a.cg.2,

(B) cdn20p0004b10.f.1.a.cg.2, (C) Multiple EGF-like domains 10, and (D) wy0aba18yb03fm1.1.a.cg.2. Relative expression levels were obtained according to the $2^{-\triangle \Delta \mathrm{Ca}}$ method using the $\mathrm{Cg}$-rp/40 as constitutively expressed gene. Relative abundances of gene copy were obtained with the same method but using the single copy $\mathrm{Cg}$-bpi gene as reference. Grey line represents linear fit, significant correlations are indicate by $P<0.05$ and $r$ indicates the correlation coefficient. 
gene in the oyster genome. This has been shown for the human neutrophil antimicrobial peptide-3 (HNP-3) $[30,31]$. Since HNP-3 was proved to play an important role in infectious and inflammatory diseases [32], it has been suggested that the absence of $D E F A 3$ gene can result in changes in the human susceptibility to pathogenic microorganisms [30]. Here, probably due to limited sampling number, we did not evidence a statistical correlation between the lack of hemocyte gene expression and the oyster capacity to survive infections, but this result prompted us to further analyze this phenomenon of absence of immune-related transcripts in oyster populations.

The existence of a genetic predisposition of oyster to survive Vibrio infections was revealed by DGE and highthroughput qPCR analyses. Performed on independent sets of 180 oysters, from different geographical origin and history, these different transcriptomic analyses concurred in the statistical identification of a gene survival signature. Indeed, in spite of the high polymorphism of gene expression, the combination of the basal expression levels of 14 hemocyte-expressed genes was shown to be correlated to oyster capacity to survive infections by the pathogenic $V$. splendidus LGP32. This 14-gene survival signature includes 8 unknown genes and the potential role of the other annotated genes in the oyster health status and survival cannot be interpreted. However, interestingly, one member of the survival signature, a putative cystatin $\mathrm{A}$, has already been identified as related to the ability of oyster to circumvent virulent Vibrio infection in previous genomic study [21]. Since $V$. splendidus LGP32 and $V$. aestuarianus are known to secrete extracellular proteases, we can assume that, highly expressed at basal level, cystatin, as protease inhibitor, may interact with the Vibrio toxins contributing to oyster survival [21]. It is noteworthy that cystatins are a superfamily of multifunctional proteins [33] that requires extensive characterization in oyster before speculating any function or role in survival. Recently, a mortality gene expression signature was identified in $C$. gigas hemocytes of oysters that died in the field during summer mortality events in USA [34]. This so-called "mortality signature" comprised a core set of genes involved in cell death, protein synthesis and cellular assembly and organization. Their expression increased in individuals previously to the occurrence of massive mortalities in the field [34]. Besides, Fleury et al. [35,36] also showed in oyster tissues, such as gonads, gills and muscle, transcripts of immune-related genes differentially expressed between two oyster lines selected for their resistance and susceptibility to the 2001 summer mortality events in France. However, these genes were identified according to an increase of their transcript abundance during various periods preceding a mortality event, revealing a physiological response of the oysters to field conditions. Instead, our study has focused on the identification of genes whose basal expression in oyster may reflect an intrinsic character of survival capacity, i.e. a genetically-based trait underlying natural variation in gene expression.

In this attempt, it was important to verify that, in our experiments, the high mRNA levels of the 14-genes identified as related to survival capacity were not due to a particular physiological status or a priming of the oysters prior to the hemolymph sampling. Indeed, priming could confer protection against $V$. splendidus LGP32 infection, as described in various invertebrate species, where pre-stimulated animals were protected against a second and lethal challenge, and in a specific manner $[37,38]$. Here, following microbial challenge or injury (sea water injection), no increase in transcript abundance was observed from the genes of the survival signature. Instead, a decrease of transcripts was observed for five of them. Such a decrease is either related to a migration of the hemocyte subpopulation expressing those genes towards the site of injection [39], or to a downregulation of expression following wound injection. Besides, nine genes were evidenced as constitutively expressed in circulating hemocytes and not regulated by a microbial challenge. Ruling out a priming possibility or an effect of physiological status, these results are in favor of genetic bases driving hemocyte high basal gene expression in some oysters.

In our study, copy number variations (CNVs) in the 14 marker genes were evidenced among the individuals tested, as previously reported by Schmitt et al. [29] for genes encoding actin and two antimicrobial peptides ( $C g$-Defs and $C g$-Prps). It is now established that $\mathrm{CNV}$ contributes to differences in gene expression and can be associated to variable phenotypes, including susceptibility to complex genetic disorders and infectious diseases [40,41]. For instance, in human, whereas an elevated number of copies of the $\beta$-defensin gene DEFB103 in the East Asia population is associated to increased resistance to influenza [42], high $\alpha$-defensin (DEFA1A3) gene copies were shown to be significantly correlated with susceptibility to severe sepsis [43]. Here, we have not found a correlation between $\mathrm{CNV}$ and gene expression profile for all of the genes of the survival signature. As elegantly shown by Mileyko et al. [44], the basal expression of some genes is not necessarily proportional to the gene copy number in the genome due to transcriptional feedbacks in complex regulatory networks. Because oysters are highly polymorphic [28], changes in gene expression can also be associated to a high degree of DNA polymorphism in the gene promoter sequence [45]. Our results indicated that the mRNA levels of the different genes from the 14-gene survival signature are likely driven by distinct transcriptional processes. 


\section{Conclusions}

In conclusion, our findings evidenced that oysters possess a complex genomic organization that is highly polymorphic, not only in terms of DNA sequence [28], but also in terms of number of gene copies and transcriptional regulation of genes. A deep analysis of the whole hemocyte transcriptome of oysters showing differences in the resistance to Vibrio infection led to the discovery of a 14-gene predictive survival signature. Currently, in human medicine, such gene expression signatures have considerably improved the diagnosis and understanding of complex genetic disorders and infectious diseases $[12,15,16]$. In the context of $C$. gigas aquaculture, the mass mortality syndrome represents a serious constraint to oyster production world-wide. Thus, understanding the genetic basis involved in oyster survival constitutes an important piece in the oyster-pathogen-environment interaction puzzle. Although oyster immunogenetics is still an emerging domain that requires great improvement in genomic resources, we showed that gene predictive-survival signature could provide a useful tool for preventing mortality events and for assessing genetic traits of interest for disease resistance selection programs.

\section{Methods}

\section{Oysters and experimental Vibrio infections}

For DGE library construction, 2 year-old adult Crassostrea gigas oysters were purchased from an Atlantic oyster farm (La Tremblade, France). Following an acclimatation period of one week in aquaria containing filtered sea water at $20^{\circ} \mathrm{C}, 180$ animals were individually tagged and hemolymph $(\sim 500 \mu \mathrm{L}$ per animal) was withdrawn from the adductor muscle without causing the death of the animals. Hemocyte samples were individually collected by centrifugation $\left(1,500 \mathrm{xg}\right.$ for $15 \mathrm{~min}$ at $\left.4{ }^{\circ} \mathrm{C}\right)$, homogenized in $1 \mathrm{~mL}$ of TRIzol reagent (Invitrogen) and frozen at $-20{ }^{\circ} \mathrm{C}$ until RNA extraction. After hemolymph collection, animals were placed in glass tanks (20 animals per tank) and allowed to recover for 8 days prior to experimental infections. Then, 90 oysters were intramuscularly injected with $8 \times 10^{7} \mathrm{CFU} / \mathrm{animal}$ of $V$. splendidus LGP32 and a second group of 90 oysters with $2 \mathrm{x}$ $10^{7} \mathrm{CFU} /$ animal of $V$. aestuarianus LPi 02/41. Mortalities were monitored daily and individually tagged animals that did not survive were noted and discarded. After the end of acute mortalities ( $96 \mathrm{~h}$ post-infection), stored hemolymph samples were categorized according to oyster survival (surviving versus non-surviving).

For high-throughput qPCR analyses and discovery of candidate genes associated to oyster survival capacity, three independent infections ( $\mathrm{n}=60$ oysters per experiment) were further conducted on oysters (2 year-old) from Mediterranean oyster farm (Sodimer, Balaruc, France) with $V$. splendidus LGP32 (5 x $10^{8} \mathrm{CFU} /$ animal $)$ following the same protocol as applied for DGE libraries construction. Finally, a last set of experiments was performed to control the expression modulation of the signature genes upon infection or injury. In this experiment, oysters were injected with a sublethal dose (5 x $10^{7} \mathrm{CFU} /$ animal) of live $V$. splendidus LGP32. Unchallenged oysters (i.e., oyster at time $0 \mathrm{~h}$ ) and oysters injected with $100 \mu \mathrm{L} \mathrm{SSW}$ (sterile sea water) were used as controls. Hemolymph was collected $24 \mathrm{~h}$ postinjection and hemocytes were collected and pooled (3 pools of 10 animals per condition) for RNA extraction. The standardization of the experimental infections and the preparation of the bacterial inoculum were performed as previously described [46]. All experimentations were performed according to the Ifremer animal care guideline and policy.

DGE library construction and oyster tag-to-gene mapping Two DGE libraries were constructed from pooled hemocyte RNA samples of oysters able (SVir-8d DGE library) and not able (NSVir-8d DGE library) to survive Vibrio infections, according to protocols previously described $[21,47]$. The obtained DGE tag signatures were matched against 29,745 unique sequences from different tissues of C. gigas stored on the platform of Sigenae-INRA Toulouse (http://public-contigbrowser.sigenae.org:9090/ Crassostrea_gigas/index.html). For tag to gene mapping, the virtual tags were extracted from all contigs and singletons. Only tags with $100 \%$ sequence identity with oyster EST sequences were assigned. Functional gene annotation was performed as described previously [21].

\section{High-throughput qPCR using 96.96 microfluidic dynamic arrays}

Complementary DNAs (cDNA) were synthesized from $250 \mathrm{ng}$ of total individual hemocyte RNA samples and preamplified by using the TaqMan PreAmp kit (Applied Biosystems). Candidate genes were selected based on the differential of tag occurrences between the DGE libraries ( $>5$-fold change). Primers used in this study are listed in the Additional File 2. The eukaryotic translation elongation factor 1-alpha (Cg-ef1 $\alpha)$ [GenBank: AB122066], the ribosomal protein L40 (Cg-rpl40) [GenBank: FP004478], and the $40 \mathrm{~S}$ ribosomal protein S6 (Cg-rps6) [GenBank: CU686508] were used as endogenous reference genes. The relative gene expression was measured by using the high-throughput microfluidic qPCR platform BioMark $^{\mathrm{TM}}$ (Fluidigm) [22]. The cycling program used consisted of $10 \mathrm{~min}$ at $95{ }^{\circ} \mathrm{C}$ followed by 40 cycles of $95{ }^{\circ} \mathrm{C}$ for $15 \mathrm{~s}$ and $1 \mathrm{~min}$ at $60^{\circ} \mathrm{C}$. Melting curves analysis was performed after completed qPCR collecting fluorescence between $60-95{ }^{\circ} \mathrm{C}$ at $0.5{ }^{\circ} \mathrm{C}$ increments. qPCR data were analyzed using the BioMark ${ }^{\mathrm{TM}} \mathrm{qPCR}$ analysis software (Fluidigm). 


\section{Data analysis and statistical modeling}

Expression of the three reference genes was quantified in each array chip in order to assess the technical efficiency of the qPCR experiments. Variations in Cq values associated to each qPCR experiment were evaluated using ANOVA among the reference genes. The delta $\mathrm{Cq}$ values $(\Delta \mathrm{Cq})$ were determined for all target genes by subtracting the $\mathrm{Cq}$ values from the geometric mean of the $\mathrm{Cq}$ values of the three reference genes. Thus, a data matrix was built up based on the $\Delta \mathrm{Cq}$ values obtained from all qPCR dynamic arrays.

Partial least-squares (PLS) models using PLS regression were used to discriminate oyster survival on the basis of $\Delta C q$ values of the target genes. PLS predictive models were assessed using the SIMCA-P software 9.0 (Umetri, Umeå, Sweden), as previously described $[26,27]$. For our analysis, $\triangle \mathrm{Cq}$ values from qPCR assays and individual oysters with contrasting survival capacities were considered as variables $\mathrm{X}$ and $\mathrm{Y}$, respectively. The PLS regression between variables $X$ and variables $Y$ yielded the PLS components $t[1], t[2], \ldots, t[n]$, which are linear combinations of variables $\mathrm{X}\left(\mathrm{t}[1]=\mathrm{w}^{*}{ }_{11} \mathrm{X}_{1}+\right.$ $\mathrm{w}^{*}{ }_{12} \mathrm{X}_{2}+\ldots+\mathrm{w}^{*}{ }_{1 \mathrm{n}} \mathrm{X}_{\mathrm{n}}, \mathrm{t}[2]=\mathrm{w}^{*}{ }_{21} \mathrm{X}_{1}+\mathrm{w}^{*}{ }_{22} \mathrm{X}_{2}+\ldots+\mathrm{w}^{*}{ }_{2 \mathrm{n}} \mathrm{X}_{\mathrm{n}}$, $\left.\mathrm{t}[\mathrm{n}]=\mathrm{w}^{*}{ }_{n 1} \mathrm{X}_{1}+\mathrm{w}^{*}{ }_{n 2} \mathrm{X}_{2}+\ldots+\mathrm{w}^{*}{ }_{n n} \mathrm{X}_{\mathrm{n}}\right)$. These components describe the variables $\mathrm{X}$ and explain the variables $\mathrm{Y}$. The number of useful PLS components was determined by cross-validation (SIMCA-P 9.0, 2001). Regression relating the variables $Y$ to the PLS components $t[1], t[2], \ldots, t[n]$ are then build as follows: $\mathrm{Y} 1=\mathrm{C}_{11} \mathrm{t}[1]+\mathrm{C}_{12} \mathrm{t}[2]+\ldots+\mathrm{C}_{1 \mathrm{n}} \mathrm{t}$ $[\mathrm{n}]+$ residuals, $\quad \mathrm{Y} 2=\mathrm{C}_{21} \mathrm{t}[1]+\mathrm{C}_{22} \mathrm{t}[2]+\ldots+\mathrm{C}_{2 \mathrm{n}} \mathrm{t}[\mathrm{n}]+$ residuals, $Y n=C_{n 1} t[1]+C_{n 2} t[2]+\ldots+C_{n n} t[n]+$ residuals. The $\mathrm{X}$-loadings and the Y-loadings are noted $\mathrm{w}^{*}$ and $\mathrm{c}$, respectively. The explanatory performance of a model is evaluated using the $R^{2}$ coefficient which corresponds to the part of the variance of variables $\mathrm{Y}$ explained by the variables $\mathrm{X}$.

The $\Delta \mathrm{Cq}$ data matrix was used for calculation of relative expression (fold change) using the $2^{-\Delta \Delta C q}$ method (assuming $100 \%$ amplification efficiency) [48]. For that, the "NS phenotype" was chosen as reference group. In order to obtain a second normalized value $(\Delta \Delta \mathrm{Cq})$, the geometric mean of the $\Delta \mathrm{Cq}$ values from the reference group was subtracted from the geometric mean of the $\Delta \mathrm{Cq}$ values from "S phenotype". Then, the relative expression ratio was calculated by using the $2^{-\Delta \Delta C q}$ formula. Various fold-change and raw Cq cut-off to assess the value of the sensibility of the RT-qPCR experimentation were applied. Then Mann-Whitney tests on the $\Delta \mathrm{Cq}$ were used to assert a significant difference between $\mathrm{S}$ and NS phenotypes.

\section{Relative gene copy number estimation}

Gene copy number estimation and relative expression of seven genes comprising the 14-gene survival signature were carried out using LightCycler 480 qPCR system (Roche) in a 384 well plate format. Both genomic DNA and total RNA was extracted from 10 individual oysters as described previously [29]. Each qPCR experiment was performed in triplicates and run under the following conditions: $95{ }^{\circ} \mathrm{C}$ for $10 \mathrm{~min}$ and then 40 cycles of denaturation at $95{ }^{\circ} \mathrm{C}$ for $10 \mathrm{~s}$, annealing at $57{ }^{\circ} \mathrm{C}$ for $20 \mathrm{~s}$ and extension at $72{ }^{\circ} \mathrm{C}$ for $25 \mathrm{~s}$, following melting curve determination. Relative expression levels were obtained using the $2^{-\Delta \Delta C \mathrm{q}}$ method using the $C g$-rpl40 as constitutively expressed reference gene. Relative abundance of gene copy was obtained with the same method but using a single copy encoded gene ( $C$. gigas bactericidal permeability-increasing protein, $\mathrm{Cg}$-bpi) as reference [GenBank: AY165040]. Correlations between relative abundance of gene copy and relative expression were obtained by using a correlation matrix from Statistica software (V7.1, Statsoft), and significant correlations were indicated by a $p<0.05$.

\section{Additional files}

Additional file 1: List of hemocyte-expressed genes associated to oyster survival phenotypes.

Additional file 2: Nucleotide sequences of primers used.

\section{Abbreviations}

CFU: colony forming units; CNV: gene copy number variation; DGE: digital gene expression; EST: expressed sequence tags; NSVir-8d: non-surviving DGE library; PLS: partial least-squares; qPCR: quantitative real-time Polymerase Chain Reaction; SNP: single nucleotide polymorphism; SVir-8d: surviving DGE library.

\section{Competing interests}

The authors declare no conflict of interest.

\section{Acknowledgements}

We are grateful to Denis Saulnier, Julie Fievet and Marc Leroy for technical assistance in the experimental infections and, Delphine Destoumieux-Garzón and Timothy J. Green for critical reading of the manuscript. This work was supported in part by graduate scholarship from CNPq-Brazil (to RDR), and by Ifremer, CNRS, and Agence Nationale de la Recherche (Genanimal project Cg-Physiogene: N07/5210875/F). Data used in this work were partly produced through molecular genetic analysis technical facilities of the "Plateforme qPHD UM2/Montpellier GenomiX" and "Plateforme Génomique INRA Auzeville".

\section{Author details}

${ }^{1} 1$ Ifremer, CNRS, Université Montpellier 2, IRD and Université Montpellier 1, UMR 5119 "Laboratoire Écologie des Systèmes Marins Côtiers, Place Eugène Bataillon, PO Box 34095, Montpellier, France. Université Montpellier 2, IRD, Ifremer, CNRS, and Université Montpellier 1, UMR 5119 "Laboratoire Écologie des Systèmes Marins Côtiers, Place Eugène Bataillon, PO Box 34095 , Montpellier, France. ${ }^{3}$ INRA, Université Montpellier 2, UMR 1133 "Laboratoire Écologie Microbienne des Insectes et Interactions Hôte-Pathogènes, Place Eugène Bataillon, PO Box 34095, Montpellier, France. ${ }^{4}$ Skuldtech, Cap Delta, PO Box 34790, Grabels, France.

Authors' contributions

$\mathrm{RDR}$, JdL, DP and EB designed research. RDR, JdL and DP performed research. $\mathrm{RDR}, \mathrm{JdL}, \mathrm{PT}, \mathrm{RB}$ and $\mathrm{DP}$ contributed new reagents/analytic tools. $\mathrm{RDR}$, JdL, PT, RB, DP and EB analyzed data. RDR, DP and EB wrote the paper. All authors read and approved the final manuscript. 
Received: 16 February 2012 Accepted: 18 June 2012

Published: 18 June 2012

\section{References}

1. Lafferty KD, Porter JW, Ford SE: Are diseases increasing in the ocean? Annu Rev Ecol Systemat 2004, 35:31-54.

2. Rosenberg E: Coral microbiology. Microbial Biotech 2009, 2:147.

3. Rosenberg E, Ben-Haim Y: Microbial diseases of corals and global warming. Environ Microbiol 2002, 4:318-326.

4. Harvell CD, Kim K, Burkholder JM, Colwell RR, Epstein PR, Grimes DJ, Hofmann EE, Lipp EK, Osterhaus AD, Overstreet RM, et al: Emerging marine diseases-climate links and anthropogenic factors. Science 1999, 285:1505-1510.

5. Samain JF, McCombie H: Summer mortality of Pacific oyster Crassostrea gigas. Versailles: Edited by Quae; 2008:379.

6. Burge CA, Griffin FJ, Friedman CS: Mortality and herpesvirus infections of the Pacific oyster Crassostrea gigas in Tomales Bay, California, USA. Dis Aquat Org 2006, 72:31-43.

7. Renault T, Novoa B: Viruses infecting bivalve molluscs. Aquat Living Resour 2004, 17:397-409.

8. Garnier M, Labreuche Y, Garcia C, Robert M, Nicolas JL: Evidence for the involvement of pathogenic bacteria in summer mortalities of the Pacific oyster Crassostrea gigas. Microb Ecol 2007, 53:187-196.

9. Hill AV: The genomics and genetics of human infectious disease susceptibility. Annu Rev Genom Hum Genet 2001, 2:373-400.

10. Vannberg FO, Chapman SJ, Hill AV: Human genetic susceptibility to intracellular pathogens. Immunol Rev 2011, 240:105-116.

11. Bochud PY, Bochud M, Telenti A, Calandra T: Innate immunogenetics: a tool for exploring new frontiers of host defence. Lancet Infect Dis 2007, 7:531-542.

12. van de Vijver MJ, He YD, van't Veer $L$, Dai H, Hart AA, Voskuil DW, Schreiber GJ, Peterse JL, Roberts C, Marton MJ, et al: A gene-expression signature as a predictor of survival in breast cancer. N Engl J Med 2002, 347:1999-2009.

13. Wain LV, Armour JA, Tobin MD: Genomic copy number variation, human health, and disease. Lancet 2009, 374:340-350.

14. Van 't Veer LJ, Dai H, van de Vijver MJ, He YD, Hart AA, Mao M, Peterse HL, van der Kooy K, Marton MJ, Witteveen AT, et al: Gene expression profiling predicts clinical outcome of breast cancer. Nature 2002, 415:530-536.

15. Berry MP, Graham CM, McNab FW, Xu Z, Bloch SA, Oni T, Wilkinson KA, Banchereau R, Skinner J, Wilkinson RJ, et al: An interferon-inducible neutrophil-driven blood transcriptional signature in human tuberculosis. Nature 2010, 466:973-977.

16. Jeffs $A R$, Glover AC, Slobbe $L$, Wang $L$, He S, Hazlett JA, Awasthi $A$, Woolley AG, Marshall ES, Joseph WR, et al: A gene expression signature of invasive potential in metastatic melanoma cells. PLOS ONE 2009, 4:e8461.

17. Hedgecock D, Gaffney PM, Goulletquer P, Guo X, Reece KS, Warr GW: The case for sequencing the Pacific oyster genome. J Shell Res 2005 24:429-441.

18. Fleury $E$, Huvet $A$, Lelong $C$, de Lorgeril J, Boulo V, Gueguen $Y$, Bachère $E$, Tanguy A, Moraga D, Fabioux C, et al: Generation and analysis of a 29,745 unique Expressed Sequence Tags from the Pacific oyster (Crassostrea gigas) assembled into a publicly accessible database: the GigasDatabase. BMC Genomics 2009, 10:341-356.

19. Hedgecock D, Lin JZ, DeCola S, Haudenschild CD, Meyer E, Manahan DT, Bowen B: Transcriptomic analysis of growth heterosis in larval Pacific oysters (Crassostrea gigas). Proc Natl Acad Sci U S A 2007, 104:2313-2318.

20. Hene L, Sreenu VB, Vuong MT, Abidi SH, Sutton JK, Rowland-Jones SL, Davis SJ, Evans EJ: Deep analysis of cellular transcriptomes - LongSAGE versus classic MPSS. BMC Genomics 2007, 8:333.

21. de Lorgeril J, Zenagui $R$, Rosa RD, Piquemal $D$, Bachère $E$ : Whole transcriptome profiling of successful immune response to Vibrio infections in the oyster Crassostrea gigas by Digital Gene Expression analysis. PLOS ONE 2011, 5:e23142.

22. Jang JS, Simon VA, Feddersen RM, Rakhshan F, Schultz DA, Zschunke MA, Lingle $W L$, Kolbert $C P$, Jen J: Quantitative miRNA expression analysis using Fluidigm microfluidics dynamic arrays. BMC Genomics 2011, 12:144.

23. de Lorgeril J, Gueguen Y, Goarant C, Goyard E, Mugnier C, Fievet J, Piquemal D, Bachère $E$ : A relationship between antimicrobial peptide gene expression and capacity of a selected shrimp line to survive a Vibrio infection. Mol Immunol 2008, 45:3438-3445.
24. Rosa RD, Santini A, Fievet J, Bulet P, Destoumieux-Garzón D, Bachère E: Big defensins, a diverse family of antimicrobial peptides that follows different patterns of expression in hemocytes of the oyster Crassostrea gigas. PLOS ONE 2011, 6:e25594.

25. Taris N, Lang RP, Camara MD: Sequence polymorphism can produce serious artefacts in real-time PCR assays: hard lessons from Pacific oysters. BMC Genomics 2008, 9:234.

26. Li X, Gill R, Cooper NG, Yoo JK, Datta S: Modeling microRNA-mRNA interactions using PLS regression in human colon cancer. BMC Med Genomics 2011, 4:44.

27. Matte-Tailliez O, Lepage E, Tenenhaus M, Tailliez P: Use of predictive modeling for Propionibacterium strain classification. Syst Appl Microbiol 2002, 25:386-395.

28. Sauvage C, Bierne N, Lapegue S, Boudry P: Single nucleotide polymorphisms and their relationship to codon usage bias in the Pacific oyster Crassostrea gigas. Gene 2007, 406:13-22.

29. Schmitt $P$, Gueguen $Y$, Desmarais $E$, Bachère $E$, de Lorgeril J: Molecular diversity of antimicrobial effectors in the oyster Crassostrea gigas. BMC Evol Biol 2010, 10:23.

30. Ballana E, Gonzalez JR, Bosch N, Estivill X: Inter-population variability of DEFA3 gene absence: correlation with haplotype structure and population variability. BMC Genomics 2007, 8:14.

31. Linzmeier RM, Ganz T: Human defensin gene copy number polymorphisms: comprehensive analysis of independent variation in alpha- and beta-defensin regions at 8p22-p23. Genomics 2005, 86:423-430.

32. Ihi T, Nakazato M, Mukae $H$, Matsukura S: Elevated concentrations of human neutrophil peptides in plasma, blood, and body fluids from patients with infections. Clin Infect Dis 1997, 25:1134-1140.

33. Ochieng J, Chaudhuri G: Cystatin superfamily. J Health Care Poor Underserved 2010, 21:51-70

34. Chaney ML, Gracey AY: Mass mortality in Pacific oysters is associated with a specific gene expression signature. Mol Ecol 2011, 20:2942-2954

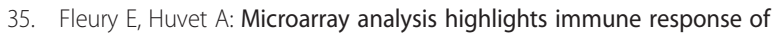
Pacific oysters as a determinant of resistance to summer mortality. Mar Biotechnol (NY) 2012, 14:212-217.

36. Fleury E, Moal J, Boulo V, Daniel JY, Mazurais D, Henaut A, Corporeau C, Boudry P, Favrel P, Huvet A: Microarray-based identification of gonad transcripts differentially expressed between lines of Pacific oyster selected to be resistant or susceptible to summer mortality. Mar Biotechnol (NY) 2010, 12:326-339.

37. Kurtz J, Franz K: Innate defence: evidence for memory in invertebrate immunity. Nature 2003, 425:37-38.

38. Pham LN, Dionne MS, Shirasu-Hiza M, Schneider DS: A specific primed immune response in Drosophila is dependent on phagocytes. PLOS Pathog 2007, 3:e26.

39. Schmitt $P$, Lorgeril JD, Gueguen $Y$, Destoumieux-Garzón D, Bachère E: Expression, tissue localization and synergy of antimicrobial peptides and proteins in the immune response of the oyster Crassostrea gigas. Dev Comp Immunol 2012, 37:363-370

40. Gonzalez E, Kulkarni H, Bolivar H, Mangano A, Sanchez R, Catano G, Nibbs RJ, Freedman BI, Quinones MP, Bamshad MJ, et al: The influence of CCL3L1 gene-containing segmental duplications on HIV-1/AIDS susceptibility. Science 2005, 307:1434-1440.

41. Stranger BE, Forrest MS, Dunning M, Ingle CE, Beazley C, Thorne N, Redon R, Bird CP, de Grassi A, Lee C, et al: Relative impact of nucleotide and copy number variation on gene expression phenotypes. Science 2007, 315:848-853.

42. Hardwick RJ, Machado LR, Zuccherato LW, Antolinos S, Xue Y, Shawa N, Gilman RH, Cabrera L, Berg DE, Tyler-Smith C, et al: A worldwide analysis of beta-defensin copy number variation suggests recent selection of a high-expressing DEFB103 gene copy in East Asia. Hum Mutat 2011, 32:743-750.

43. Chen Q, Hakimi M, Wu S, Jin Y, Cheng B, Wang H, Xie G, Ganz T, Linzmeier RM, Fang $X$ : Increased genomic copy number of DEFA1/DEFA3 is associated with susceptibility to severe sepsis in Chinese Han population. Anesthesiology 2010, 112:1428-1434.

44. Mileyko Y, Joh RI, Weitz JS: Small-scale copy number variation and large-scale changes in gene expression. Proc Natl Acad Sci U S A 2008, 105:16659-16664. 
45. Cussigh A, Falleti E, Fabris C, Bitetto D, Cmet S, Fontanini E, Bignulin S, Fornasiere E, Fumolo E, Minisini R, et al: Interleukin 6 promoter polymorphisms influence the outcome of chronic hepatitis $C$. Immunogenetics 2011, 63:33-41.

46. Duperthuy M, Binesse J, Le Roux F, Romestand B, Caro A, Got P, Givaudan A, Mazel D, Bachère E, Destoumieux-Garzón D: The major outer membrane protein $\mathrm{OmpU}$ of Vibrio splendidus contributes to host antimicrobial peptide resistance and is required for virulence in the oyster Crassostrea gigas. Environ Microbiol 2010, 12:951-963.

47. Piquemal D, Commes T, Manchon L, Lejeune M, Ferraz C, Pugnere D, Demaille J, Elalouf JM, Marti J: Transcriptome analysis of monocytic leukemia cell differentiation. Genomics 2002, 80:361-371.

48. Schmittgen TD, Livak KJ: Analyzing real-time PCR data by the comparative $C_{T}$ method. Nat Protocols 2008, 3:1101-1108.

doi:10.1186/1471-2164-13-252

Cite this article as: Rosa et al: A hemocyte gene expression signature correlated with predictive capacity of oysters to survive Vibrio infections. BMC Genomics 2012 13:252.

\section{Submit your next manuscript to BioMed Central and take full advantage of:}

- Convenient online submission

- Thorough peer review

- No space constraints or color figure charges

- Immediate publication on acceptance

- Inclusion in PubMed, CAS, Scopus and Google Scholar

- Research which is freely available for redistribution 